\title{
Prevalence of chronic obstructive pulmonary disease among patients with systemic arterial hypertension without respiratory symptoms
}

This article was published in the following Dove Press journal:

International Journal of COPD

31 July 2015

Number of times this article has been viewed

\author{
Marcelo Fouad Rabahi ${ }^{1,2}$ \\ Sheila Alves Pereira' \\ José Laerte Rodrigues Silva \\ Júnior ${ }^{1,2}$ \\ Aline Pacheco de Rezende' \\ Adeliane Castro da Costa ${ }^{2}$ \\ Krislainy de Sousa Corrêa ${ }^{2,3}$ \\ Marcus Barreto Conde 4,5 \\ 'School of Medicine, Federal \\ University of Goiás, Goiania, Brazil; \\ ${ }^{2}$ Clínica do Aparelho Respiratório \\ (CLARE), Goiania, Brazil; ${ }^{3}$ Pontifical \\ Catholic University of Goiás, Goiania, \\ Brazil; ${ }^{4}$ Faculdade de Medicina de \\ Petrópolis/FASE, Petrópolis, Brazil; \\ ${ }^{5}$ Instituto de Doenças do Tórax da \\ Universidade Federal do Rio de \\ Janeiro, Rio de Janeiro, Brazil
}

Correspondence: Marcelo Fouad Rabahi Av.B, número 483, Setor Oeste, Goiania, Goiás CEP 74I I0-030, Brazil

$\mathrm{Tel}+556235213333$

Fax +5562352I 3333

Email mfrabahi@gmail.com
Background: The diagnosis of chronic obstructive pulmonary disease (COPD) is often delayed until later stages of the disease. The purpose of the present study was to determine the prevalence of COPD among adults on treatment for systemic arterial hypertension independently of the presence of respiratory symptoms.

Methods: This cross-sectional study included adults aged $\geq 40$ years with tobacco/occupational exposure and systemic arterial hypertension diagnosed at three Primary Health Care facilities in Goiania, Brazil. Patients were evaluated using a standardized respiratory questionnaire and spirometry. COPD prevalence was measured considering the value of forced vital capacity and/ or forced expiratory volume in 1 second $<0.70$.

Results: Of a total of 570 subjects, 316 (55\%) met inclusion criteria and were invited to participate. Two hundred and thirty-three (73.7\%) patients with arterial hypertension reported at least one respiratory symptom, while 83 (26.3\%) reported no respiratory symptoms; 41 (17.6\%) patients with arterial hypertension and at least one respiratory symptom, and $10(12 \%)$ patients with arterial hypertension but no respiratory symptoms were diagnosed with $\operatorname{COPD}(P=0.24)$. The prevalence of COPD in people with no previous COPD diagnosis was greater among those with no respiratory symptoms $(100 \%)$ than among those with respiratory symptoms $(56.1 \%)(P=0.01)$.

Conclusion: Our findings suggest that regardless of the presence of respiratory symptoms, individuals aged $\geq 40$ years with tobacco/occupational exposure and arterial hypertension may benefit from spirometric evaluation.

Keywords: COPD, hypertension, public health

\section{Background}

The World Health Organization (WHO) reports that chronic obstructive pulmonary disease (COPD) was responsible for more than three million fatalities in 2011, accounting for $5.8 \%$ of all deaths. ${ }^{1,2}$ Although $30 \%$ of adults $\geq 35$ years of age with tobacco/ occupational exposure and at least one respiratory symptom exhibited airway obstruction on spirometry, this test is often delayed until later stages of the disease because early symptoms of COPD are not frequently recognized. ${ }^{3-5}$ However, it has already been demonstrated that airflow obstruction may be observed on spirometry in COPD patients in the initial stages of the disease, even in the absence of respiratory symptoms. ${ }^{5}$ It is known that arterial hypertension occurs in more than $50 \%$ of COPD patients diagnosed at a primary health care level. ${ }^{6}$ However, the prevalence of COPD among subjects with arterial hypertension, a disease often diagnosed and followed by primary health care providers, is unknown. The purpose of the present study was to determine the prevalence of COPD among adults with tobacco/occupational exposure and arterial 
hypertension with and without respiratory symptoms in three Primary Health Care facilities in Goiania, Brazil.

\section{Methods}

Design

Cross-sectional study.

\section{Subject selection}

Adults aged $\geq 40$ years with tobacco/occupational exposure and systemic arterial hypertension diagnosed according to the Brazilian Society of Cardiology criteria and who were undergoing treatment at a Primary Health Care facility were eligible for the study. ${ }^{7}$ Signed informed consent was necessary for enrollment. Exclusion criteria were reported to be asthma, presence of reversibility of the airway obstruction demonstrated on spirometry test; pneumothorax; angina; recent (within 3 months) myocardial infarction or pulmonary embolism or hemoptysis or brain, eye, ear, thoracic, or abdominal surgery; presence of known thoracic, abdominal, or cerebral aneurysms; severe hypertension (mean arterial pressure $>130 \mathrm{mmHg}$ ) at the time of spirometry; acute illness or symptoms that might interfere with test performance (nausea, vomiting, coughing, or acute diarrhea); and patients with mental confusion or dementia. ${ }^{8}$ Subjects were also excluded if they had incomplete interviews or could not complete the spirometric test. Patients were consecutively enrolled from January 1, 2011 to May 31, 2012.

\section{Setting and subject selection}

Brazil's health care system is organized into primary, secondary, and tertiary levels. The primary health service is named Family Health Program (FHP). Each FHP facility is responsible for a community of about 1,000 families, and has a family health team of one doctor, one nurse, one auxiliary nurse, and four to six community health agents. Community health agents visit 150 families every month on average, and the FHP provides promotive, preventive, curative, and rehabilitative services. This study was conducted at CIAMS (Center for Integrated Health Care Health) Novo Horizonte, UABSF (Primary Care Unit of the Family Health Program) Caravelas, and UABSF Santa Rita facilities in the same geographic area of Goiania, a city in Brazil's Midwest region.

\section{Data collection}

After signing the informed consent, participants completed a pretested, standardized respiratory questionnaire including the following: demographics; smoking habits; exposure to biomass smoke; education; occupational exposure to chemicals and particulate matter; respiratory symptoms; use of medications; previous spirometry testing; previous medical diagnosis of tuberculosis, asthma, chronic bronchitis, emphysema, or COPD; self-reported exacerbation and hospitalization due to COPD and comorbid conditions (heart disease, stroke, diabetes, and asthma). Anthropometrics, blood pressure, spirometry, and oxygen saturation measurements were performed in all enrolled subjects. Spirometry was performed using the portable, battery-operated ultrasound Easy One spirometer (NDD Medical Technologies, Zurich, Switzerland). Spirometry was performed at baseline and 15 minutes after the administration of $400 \mu \mathrm{g}$ of salbutamol, according to the criteria of the American Thoracic Society and European Respiratory Society for acceptability and reproducibility. ${ }^{9}$ Positive bronchodilator responsiveness was defined using the following criteria: forced vital capacity (FVC) and/or forced expiratory volume in 1 second $\left(\mathrm{FEV}_{1}\right) \geq 12 \%$ plus $\geq 200 \mathrm{~mL}$ improvement. ${ }^{10}$ The presence of COPD was based on the postbronchodilator $\mathrm{FEV}_{1} / \mathrm{FVC}<0.70$, a fixed value proposed by the Global Initiative for Obstructive Lung Disease (GOLD) criteria, among subjects 40 years old or more with tobacco/occupational exposure and no asthma diagnosis. ${ }^{11}$ Reversibility of the airway obstruction diagnosis was defined as the presence of positive bronchodilator responsiveness as defined by the American Thoracic Society. ${ }^{12}$ A significant biomass exposure was defined as a subject with more than 80 hours/year with a minimum exposure of 10 years. ${ }^{13}$ A subject was included in the group with respiratory symptoms in the presence of any of the following symptoms: dyspnea, cough, wheezing, or sputum production, and was included in the group without respiratory symptoms if all were absent.

\section{Statistical analysis}

The results were analyzed using Stata version 13.0 (StataCorp, College Station, TX, USA). For all statistical tests, $P<0.05$ was considered statistically significant. $t$-tests were used to compare two means. Chi-square or Fisher's exact test (when applicable) was used for dichotomous variables. Pairwise correlation analysis was performed between pulmonary function parameters and the blood pressure values, and the Bonferroni method was used for adjusting significance levels.

\section{Ethical aspects}

This study was conducted according to good clinical practices, and was approved by the Ethics Committee of the Hospital of the Federal University of Goiás under number 195/2011. 


\section{Results}

Over a 17-month period, 1,325 patients were admitted to all three Primary Health Care facilities, of which 570 (40\%) reported treatment for arterial hypertension in one of three facilities (Figure 1). Among these 570 subjects, 316 (55\%) met the inclusion criteria and were invited to participate in the study. Two hundred and five were nonsmokers without significant biomass exposure, 10 were $<40$ years of age, 17 patients refused to sign the consent form, and 22 patients could not perform spirometry; thus, 316 subjects were enrolled in the study. Two hundred and thirty-three patients $(73.7 \%)$ with arterial hypertension reported at least one respiratory symptom, while $83(26.3 \%)$ reported no respiratory symptoms. Characteristics of the sample are presented in Table 1. Forty-one patients (17.6\%) with arterial hypertension and a respiratory symptom, and 10 patients $(12 \%)$ with arterial hypertension and no respiratory symptoms were diagnosed with COPD $(P=0.24)$. However, the prevalence of
COPD cases with no previous diagnosis was greater among patients with no respiratory symptoms than among those with respiratory symptoms $(100 \% ; 56.1 \%)(P=0.01)$. There were no additional differences related to other variables such as age, smoking history, and others as shown in Table 1 . We found no association between pulmonary function parameters and the blood pressure values.

\section{Discussion}

This study shows that there was no difference in the prevalence of COPD among patients with arterial hypertension and tobacco/occupational exposure; they either had respiratory symptoms or not. More than half of the patients with respiratory symptoms were unaware of their diagnosis, whereas all the patients without symptoms did not know they had COPD. In fact, systemic arterial hypertension has been described as a major comorbidity associated with COPD, as demonstrated by a population-based case-control study conducted

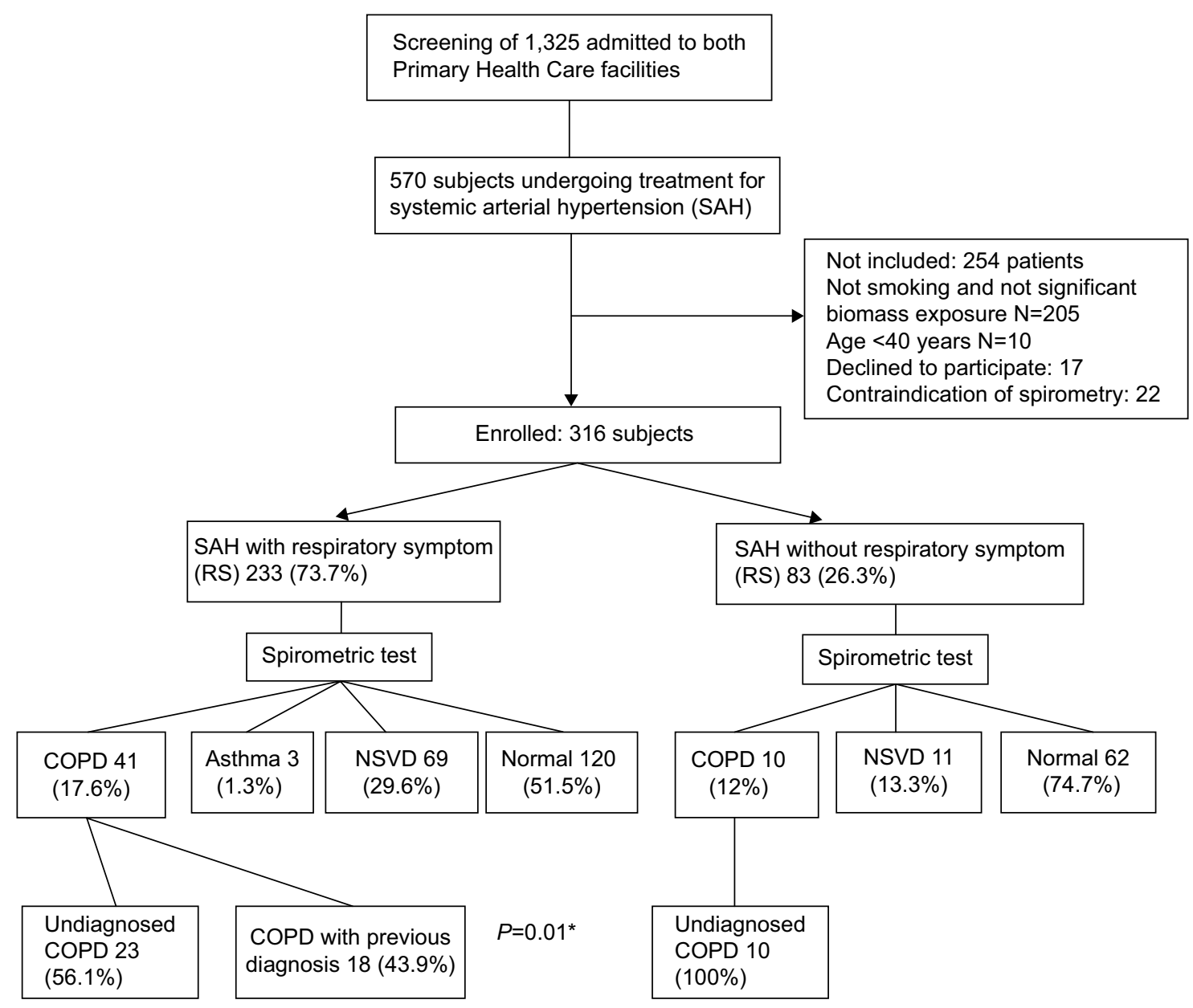

Figure I Study design and subjects.

Note: *Fisher exact test.

Abbreviations: COPD, chronic obstructive pulmonary disease; NSVD, nonspecific ventilator disturbance. 
Table I Characterization of COPD with and without respiratory symptoms in hypertensive patients

\begin{tabular}{|c|c|c|c|}
\hline \multirow[t]{2}{*}{ Variables } & $\begin{array}{l}\text { Group with respiratory } \\
\text { symptoms, } n=233(73.7 \%)\end{array}$ & $\begin{array}{l}\text { Group without respiratory } \\
\text { symptoms, } n=83(26.3 \%)\end{array}$ & \multirow[t]{2}{*}{$P$} \\
\hline & COPD, $n=4 \mid(17.6)$ & COPD, $n=10$ (I2) & \\
\hline Age (years) & $68.2 \pm 7.8$ & $69.8 \pm 6.1$ & 0.56 \\
\hline $50-59$ & $6(14.6)$ & $0(0)$ & 0.33 \\
\hline$\geq 60$ & $35(85.4)$ & $10(100)$ & \\
\hline Male (race) & $22(53.7)$ & $7(70)$ & 0.48 \\
\hline White & $14(34.2)$ & $4(40)$ & \\
\hline Mestizo & $20(48.8)$ & $6(60)$ & 0.69 \\
\hline Black & $6(14.6)$ & $0(0)$ & \\
\hline Asian & I (2.4) & $0(0)$ & \\
\hline Education (years) & $3.3 \pm 3.0$ & $4.4 \pm 2.8$ & 0.30 \\
\hline BMI $\left(\mathrm{m} / \mathrm{kg}^{2}\right)$ & $27.1 \pm 5.6$ & $24.0 \pm 5.8$ & 0.12 \\
\hline Systolic arterial pressure & $145.1 \pm 23.3$ & $136.7 \pm 29.0$ & 0.33 \\
\hline Diastolic arterial pressure & $80.7 \pm 12.4$ & $77.7 \pm 12.2$ & 0.47 \\
\hline Oxygen saturation (\%) & $93.8 \pm 2.8$ & $95.7 \pm 2.1$ & 0.06 \\
\hline Smoking (pack-years) & $32.8 \pm 26.8$ & $36.5 \pm 18.2$ & 0.68 \\
\hline Beginning smoking (age) & $13.7 \pm 7 . \mid$ & $12.7 \pm 4.0$ & 0.67 \\
\hline Exposure to biomass (hour/year) & $65.8 \pm 75.4$ & $46.6 \pm 60.6$ & 0.46 \\
\hline Occupational exposure to dust (years) & $20.9 \pm 20.9$ & $15.5 \pm 19.5$ & 0.47 \\
\hline Years living in rural area & $25.6 \pm 19.3$ & $23.2 \pm 14.1$ & 0.72 \\
\hline \multicolumn{4}{|l|}{ Smoking status } \\
\hline Current & $12(29.3)$ & $5(50)$ & 0.44 \\
\hline Former & $24(58.5)$ & $5(50)$ & \\
\hline Never & $5(12.2)$ & $0(0)$ & \\
\hline \multicolumn{4}{|l|}{ Antihypertensive medication } \\
\hline$\beta$-blocker (selective) & $3(7.3)$ & $\mathrm{I}(\mathrm{I0})$ & 0.13 \\
\hline$\beta$-blocker ( $\mathrm{n}$-selective) & $17(4 \mid .5)$ & $I(10)$ & \\
\hline Other & $21(5 \mid .2)$ & $8(80)$ & \\
\hline Heart disease & II (26.8) & $2(20)$ & 1.00 \\
\hline Diabetes & $4(9.7)$ & $2(20)$ & 0.58 \\
\hline Vascular disease & $3(7.3)$ & $2(20)$ & 0.25 \\
\hline Previous diagnosis of TB & $2(4.9)$ & $0(0)$ & 1.00 \\
\hline
\end{tabular}

Note: Data presented as mean \pm SD or $\mathrm{n}(\%)$.

Abbreviations: COPD, chronic obstructive pulmonary disease; BMI, body mass index; TB, tuberculosis; SD, standard deviation.

in Switzerland with 340,948 COPD hospitalizations. The authors found that among 82 comorbidities studied, arterial hypertension was the comorbidity with the highest prevalence among COPD patients (24\%) versus $16 \%$ in patients without COPD (95\% confidence interval 1.70 [1.6-1.7], $P<0.001) .{ }^{14}$ Similar results were observed in the KNHANES V cohort (Korean National Health and Nutrition Examination Survey): among 15 comorbidities, only arterial hypertension and history of pulmonary tuberculosis were independently associated with COPD after adjustment for confounders. ${ }^{15}$ Furthermore, a Japanese study demonstrated that $25 \%$ of patients with cardiovascular disease have COPD and were not previously diagnosed. These findings emphasize the need for active case finding strategies among higher-risk groups in order to diagnose COPD in the earlier stages of the disease. ${ }^{16}$

Our findings suggest that regardless of the presence of respiratory symptoms, people aged 40 or above with tobacco/occupational exposure and arterial hypertension may benefit from a spirometry to screen a potential case of COPD.

The current study has an important limitation. The diagnosis of COPD is based on the association between risk factor, airway obstruction in spirometry, and the presence of symptoms among subjects aged older than 40 years (GOLD). ${ }^{17}$ Our sample included individuals without symptoms. However, it should be pointed out that there are no data to prove or refute the efficacy of screening COPD cases among asymptomatic subjects using the spirometry test (GOLD). ${ }^{17}$ Considering that all individuals who reported asthma and those who had reversibility of the spirometry test were excluded from our study, we believe that the positive predictive value of the airway obstruction as demonstrated by the spirometry in this particular sample (subjects with the most common COPD comorbidity sharing COPD risk factors), even without respiratory symptoms, is probably very high for COPD diagnosis. 
Furthermore, respiratory symptoms cannot be detected in the earliest stages of COPD. ${ }^{18}$ It is therefore necessary to perform studies assessing the value of the spirometry test for screening and diagnosis (among subjects without and with respiratory symptoms, respectively) of COPD among high-risk populations in different epidemiologic scenarios in order to confirm these current findings. ${ }^{18}$

\section{Conclusion}

Our findings suggest that regardless of the presence of respiratory symptoms, individuals aged $\geq 40$ years with tobacco/ occupational exposure and arterial hypertension may benefit from spirometric evaluation for diagnosis and screening of COPD cases in the earliest stages of the disease.

\section{Acknowledgments}

The authors thank the staff of CIAMS (Center for Integrated Health Care Health) Novo Horizonte, UABSF (Primary Care Unit of the Family Health Program) Caravelas, and UABSF Santa Rita, and the patients who participated in this study. Funding for this study was provided by Novartis.

\section{Author contributions}

MFR contributed to conceiving this study and participated in the design, data collection, data interpretation, and drafting of the manuscript. SAP, APR, JLRJ, and ACC contributed to data collection, data interpretation, and drafting of the manuscript. KSC participated in the study design and coordination, and helped draft the manuscript. MBC participated in conceiving this study and participated in the study design, coordination, and statistical analysis and review of the manuscript. All authors read and approved the final manuscript.

\section{Disclosure}

This study was financially supported by Novartis. The authors did not receive any reimbursement or financial benefits, and declare no competing interests. Novartis had no role in the design, methods, data management, analysis, or the decision to publish. The authors report no conflicts of interest in this work.

\section{References}

1. World Health Organization. The Top 10 Causes of Death. Geneva, Switzerland: World Health Organization. Available from: http://who. int/mediacentre/factsheets/fs310/en/. Accessed June 26, 2015.

2. Alwan A. Global Status Report on Noncommunicable Diseases 2010. Geneva, Switzerland: World Health Organization; 2011.

3. Soriano JB, Zielinski J, Price D. Screening for and early detection of chronic obstructive pulmonary disease. Lancet. 2009;374:721-732.

4. Mannino DM. Undiagnosed chronic obstructive pulmonary disease in England: new country, same story. Thorax. 2006;61(12):1032-1034.

5. Ulrik CS, Lokke A, Dahl R, et al. Early detection of COPD in general practice. Int J Chron Obstruct Pulmon Dis. 2011;6:123-127.

6. Hill K, Goldstein RS, Guyatt GH, et al. Prevalence and underdiagnosis of chronic obstructive pulmonary disease among patients at risk in primary care. Can Med Assoc J. 2010;182:673-678.

7. Sociedade Brasileira de Cardiologia, Sociedade Brasileira de Hipertensão, Sociedade Brasileira de Nefrologia. VI Diretrizes Brasileiras de Hipertensão. Arq Bras Cardiol. 2010;95(1):1-51.

8. Vestbo J, Hurd SS, Agusti AG, et al. Global strategy for the diagnosis, management, and prevention of chronic obstructive pulmonary disease: GOLD executive summary. Am J Respir Crit Care Med. 2013;187(4):347-365.

9. Miller MR, Hankinson J, Brusasco V, et al. ATS/ERS task force: standardisation of spirometry. Eur Respir J. 2005;26(2):319-338.

10. Pellegrino R, Viegi G, Brusasco V, et al. Interpretative strategies for lung function tests. Eur Respir J. 2005;26(5):948-968.

11. Rabe KF, Hurd S, Anzueto A, et al. Global strategy for the diagnosis, management, and prevention of chronic obstructive pulmonary disease: GOLD executive summary. Am J Respir Crit Care Med. 2007;176:532-555.

12. American Thoracic Society/European Thoracic Society. Standardisation of lung function testing. Eur Respir J. 2005;26(2):319-338.

13. Ramírez-Venegas A, Sansores RH, Pérez-Padilla R, et al. Survival of patients with chronic obstructive pulmonary disease due to biomass smoke and tobacco. Am J Respir Crit Care Med. 2006;173(4): 393-397.

14. Baty F, Putora PM, Isenring B, et al. Comorbidities and burden of COPD: a population based case-control study. PLoS One. 2013;8(5):e63285.

15. Jo YS, Choi SM, Lee J, et al. The relationship between chronic obstructive pulmonary disease and comorbidities: a cross-sectional study using data from KNHANES 2010-2012. Respir Med. 2015;109(1):96-104.

16. Onishi K, Yoshimoto D, Hagan GW, Jones PW. Prevalence of airflow limitation in outpatients with cardiovascular diseases in Japan. Int $J$ Chron Obstruct Pulmon Dis. 2014;9:563-568.

17. Global Strategy for the Diagnosis, Management and Prevention of COPD, Global Initiative for Chronic Obstructive Lung Disease (GOLD) 2015. Available from: http://www.goldcopd.org/

18. Casaburi R, Duvall K. Improving early-stage diagnosis and management of COPD in primary care. Postgrad Med. 2014;126(4):141-154.

International Journal of COPD

\section{Publish your work in this journal}

The International Journal of COPD is an international, peer-reviewed journal of therapeutics and pharmacology focusing on concise rapid reporting of clinical studies and reviews in COPD. Special focus is given to the pathophysiological processes underlying the disease, intervention programs, patient focused education, and self management protocols.

Submit your manuscript here: http://www.dovepress.com/international-journal-of-chronic-obstructive-pulmonary-disease-journal

This journal is indexed on PubMed Central, MedLine and CAS. The manuscript management system is completely online and includes a very quick and fair peer-review system, which is all easy to use. Visit $\mathrm{http}: / / \mathrm{www}$. dovepress.com/testimonials.php to read real quotes from published authors. 